\title{
Foliage Plants Improve Concentration and Emotional Condition of Elementary School Students Performing an Intensive Assignment
}

Seon-Ok Kim

Department of Bio and Healing Convergence, Graduate School, Konkuk University, Seoul, 05029, South Korea

Yun-Ah Oh

Department of Animal- and Plant-Assisted Therapy, Graduate School of Agriculture and Animal Science, Konkuk University, Seoul 05029, South Korea

Sin-Ae Park

Department of Bio and Healing Convergence, Graduate School, Konkuk University, Seoul, 05029, Republic of Korea; and Department of Environmental Health Science, Sanghuh College of Life Science, Konkuk University, Seoul 05029, South Korea

Additional index words. attention ability, electroencephalography, horticultural therapy, semantic differential method, socio-horticulture

\begin{abstract}
This study was conducted to compare the concentration and emotional condition of elementary school students performing an intensive assignment in the presence or absence of foliage plants, using electroencephalography (EEG) and a modified semantic differential method (SDM). In a crossover experimental design, 30 elementary students performed a 3-min intensive age-appropriate arithmetic assignment in the presence or absence of foliage plants. Continuous EEG monitoring in the frontal lobe was performed using a wireless dry EEG device. Immediately thereafter, subjective evaluation of emotions was performed using the SDM. The concentration of the male elementary students was significantly higher when the assignment was performed in the presence vs. absence of plants as evidenced by the increase in the ratio of spectral edge frequency of 50 and a decrease in the relative theta power spectrum in the right frontal lobe. The SDM results revealed a significant psychological relaxation when the assignment was performed in the presence of plants. Therefore, the presence of foliage plants in the space where the elementary students performed the intensive assignment led to positive effects on concentration and emotional condition.
\end{abstract}

As positive effects of contact with nature are known, studies have evaluated the influence of plant arrangement or natural landscapes in workplaces and working environments (Chang and Chen, 2005; Tennessen and Cimprich, 1995). Asaumi (1995a, 1995b) reported that plant arrangement improves

Received for publication 27 Nov. 2019. Accepted for publication 31 Dec. 2019.

Published online 10 February 2020

The study was conducted with the support of the Joint Research Project ("Determining the Effects of an Urban Agriculture Program for the Health of Elementary School Students," project no. PJ012808), Rural Development Administration, Republic of Korea. This study was also supported by the KU Research Professor Program, Konkuk University.

S.A.P. is the corresponding author. E-mail: sapark42@konkuk.ac.kr.

This is an open access article distributed under the CC BY-NC-ND license (https://creativecommons. org/licenses/by-nc-nd/4.0/). a room's aesthetic quality and makes subjects feel more relaxed. In a hospital, inpatients who were assigned to a room with a natural view recovered faster than those assigned to a room with windows facing buildings (Ulrich, 1984). People arrange plants in their office to reduce or recover from stress from back pain, eyestrain, mental fatigue, and shoulder stiffness (Asaumi et al., 1994; Kondo, 1989).

Previous studies have reported that contact with plants provides a variety of benefits to humans and especially to children. Montessori (2013) reported that because nature directly educates humans, it is necessary to offer nature-based childhood education for a healthy body and mind. The results of EEG and subjective evaluations of emotions under green visual stimuli revealed improved concentration and psychological relaxation in elementary school students when they looked at real foliage plants compared with other visual stimuli (Oh et al., 2019). According to Markevych et al. (2014), as the distance from residence to green space decreased, the occurrence of behavioral problems (e.g., emotional dysregulation, hyperactivity/inattention, and peer relationship problems) in children decreased. Another study showed that when 25 children, aged 7 to 12 years with attentiondeficit/hyperactivity disorder (ADHD), walked in the city or park for $20 \mathrm{~min}$ and then performed the Digit Span Backward, the achievement of the task performed after taking a walk in the park was higher than that performed after taking a walk in the city (Taylor and Kuo, 2009).

Children in many countries are under a high level of academic stress in recent years (Bradshaw et al., 2013; Kim, 2015). Students in South Korea have the highest level of academic achievement and graduation rate [Jeon, 2009; Organization for Economic Cooperation and Development (OECD), 2017]. The Program for International Student Assessment reported that the youth in South Korea spend $60 \mathrm{~h}$ per week studying. This is the greatest amount of time among the OECD countries (Jeon, 2009; OECD, 2017). In addition, the results of the International Survey of Children's Well-being by the United Nations Children's Fund revealed that the subjective well-being of Korean children was the lowest among the OECD countries (Bradshaw et al., 2013; Kim, 2015). It is reported that children from 0 to 9 years of age spend only $0.53 \mathrm{~h}$ outdoors on weekdays; they spend most of their time indoors (Suh et al., 2016). Prolonged time in an artificial indoor environment can increase stress and negatively affect emotions (Dye, 2008). Therefore, indoor environments in which children spend most of their time, especially learning environments, play a significant role in children's stress, emotional condition, and subjective well-being (Sin and Kang, 2001).

However, studies that focus on measuring the psychophysiological and emotional responses of children are limited. Therefore, in this study, we determined the effects of foliage plants arranged in a space where students performed assignments on the concentration and emotional condition of elementary school students.

\section{Materials and Methods}

Subjects. Thirty elementary school students, aged 10 to 13 years, participated in this study. To recruit the subjects, a flyer including study information was distributed in elementary schools and churches in Gwangjin-gu, Seoul, South Korea. The subjects who wished to participate in this study were required to complete a consent form for permission from their parents. A previous study reported that there were differences in cortical activity relating to dominant and nondominant hand movement (Tarkka and Hallett, 1990), and thus a criterion for participation was that the subjects should be right-handed. Additionally, the participants were required to fast for $2 \mathrm{~h}$ before starting the experiment because ingredients such as caffeine naturally found in various foods 
could stimulate the brain and affect the data (Heckman et al., 2010). The subjects also responded to a questionnaire, which included questions on age; the height, weight, and body mass index (BMI) (ioi 353; Jawon Medical, Gyeongsan, South Korea) of the subjects were measured before the experiment. After completion of the study, the subjects received $\$ 20$ as an incentive. This study was approved by the Bioethics Committee of Konkuk University (no. 7001355-201710HR-206).

Experimental procedure. We employed a crossover experimental study design. Each subject performed the study procedure as presented in Fig. 1 (Oh et al., 2019). Before starting the intensive assignment, subjects rested for $1 \mathrm{~min}$ by staring at a white wall. The subjects then performed an intensive assignment for $3 \mathrm{~min}$ in the presence or absence of foliage plants (Fig. 2). After finishing the intensive assignment, the subjects completed a questionnaire for reporting their subjective emotional condition. After the first experiment, each subject rested for $1 \mathrm{~min}$ and then started another intensive assignment for $3 \mathrm{~min}$ in the presence or absence of foliage plants. The male and female students took the test in a random order separately.

Experimental condition. The experiment was conducted from Oct. to Dec. 2017. A space for the experiment $(180 \mathrm{~cm} \times 160 \mathrm{~cm})$ was prepared in a room in Konkuk University, Seoul, South Korea. A white hardboard was attached to the wall across from the subject's face, and an ivory-colored curtain was placed on both sides to minimize external stimuli. The room conditions were regu- lated: average temperature $21.8 \pm 3.6^{\circ} \mathrm{C}(\mathrm{O}$ 257; DRETEC Co., Japan), average relative humidity $24.8 \pm 9.6 \%$ (O-257; DRETEC Co.), and average illumination $1244.4 \pm$ 821.1 lx (ST-126; SINCON, South Korea).

The foliage plants, Scindapsus (Epipremnum aureum), were grown in a white-colored container $(55 \times 15 \mathrm{~cm})$ (Fig. $3 \mathrm{~A})$. The total height of the container, including the foliage plants, was $35 \mathrm{~cm}$. It was placed on an experimental table, $50 \mathrm{~cm}$ from the sitting position of the subject (Fig. 3B).

Intensive assignment. The intensive assignment involved arithmetic problems such as multiplication and division according to the subject's school grade. Fifteen questions for each grade (third, fourth, fifth, and sixth) were randomly selected from textbooks published in South Korea (e.g., $40+160 /(61-$ $45) \times 6 ; 2345+3815$; and $58 \times 20)($ Choi, 2015, 2017; Kang and Choi, 2015, 2017). The selected 15 questions for each grade were edited for a consistent format. The subjects solved the questions for $3 \mathrm{~min}$, and the average number of solved questions was $6.2 \pm 3.4$.

Measurement. To measure the concentration of each subject while solving the intensive age-appropriate arithmetic assignment in the presence or absence of foliage plants, a wireless dry EEG device (Quick-20; Cognionics, San Diego, CA) was used to detect brain activation (Fig. 4A). The EEG device uses a dry electrode system and not a wet electrode system with an electrolyte gel; therefore, it minimizes the risk of electric shock and allows subjects to remove the electrode from the scalp quickly if they feel uncom-

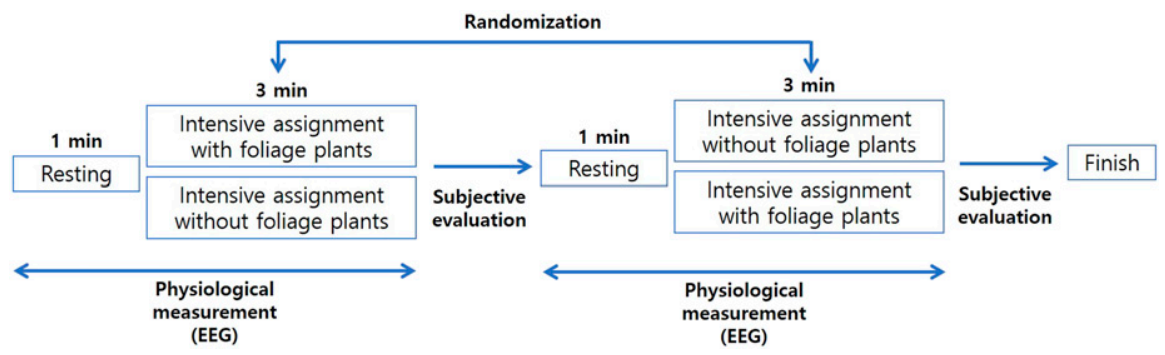

Fig. 1. Study procedure. EEG = electroencephalography. fortable. The potential difference is determined by placing the dry electrode in contact with the scalp, amplifying the measured electric signals, and collecting the processed data. This device is mainly used in the field of neuroscience (Onton et al., 2016; Stevens et al., 2016) and has been certified for safety by the European Commission and Federal Communications Commission. A brain-mapping program (Bio-scan; Bio-Tech, Daejeon, Korea) was used to map the mean EEG measurements to the subject's brain during the experiment.

The EEG monitoring was performed in two areas of the head by following the 10/ 20 international electrode arrangement (Fig. 4B) (Jasper, 1958). According to the international electrode method, EEG monitoring was performed at F3 (left frontal) and F4 (right frontal) in this study because the frontal lobe is involved in cognition and judgmental abilities (Lee and Kim, 2017a).

The Korean version of a modified simple SDM was used to measure the subjective emotional conditions of each subject (Osgood et al., 1957). The SDM consisted of three questions for "unpleasant-pleasant," "artificial-natural," and "nervous-easy" with a 13-point Likert scale. Higher scores indicated better emotional conditions.

Data analysis. EEG data were analyzed using Cognionics Data Acquisition (Cognionics) and Telescan 2.2 software (Cognionics). The collected EEG raw data were analyzed using power spectrum analysis to identify theta, beta, and low-beta powers and spectral edge frequency of 50 (SEF50) related to attention ability. The relative theta (RT), beta (RB), and low-beta (RLB) power spectra were calculated by the ratio of power in the 4to $50-\mathrm{Hz}$ band to power in the 4 to 7,14 to 30 , and 12 to $15 \mathrm{~Hz}$, respectively (Park, 2005). Furthermore, the ratio of beta and theta power (RBT) was calculated by ratio of power in the 4- to 7-Hz band to power in the 14 to $30 \mathrm{~Hz}$. The SEF50 is the frequency of the point on the power spectrum graph in which the area from 4 to $50 \mathrm{~Hz}$ occupies $50 \%$ of the area in the entire frequency range (Yu et al., 2012).
A

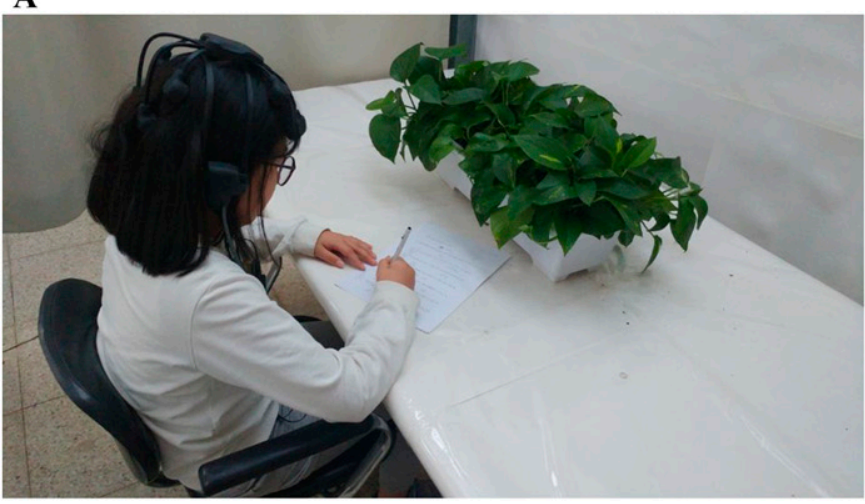

B

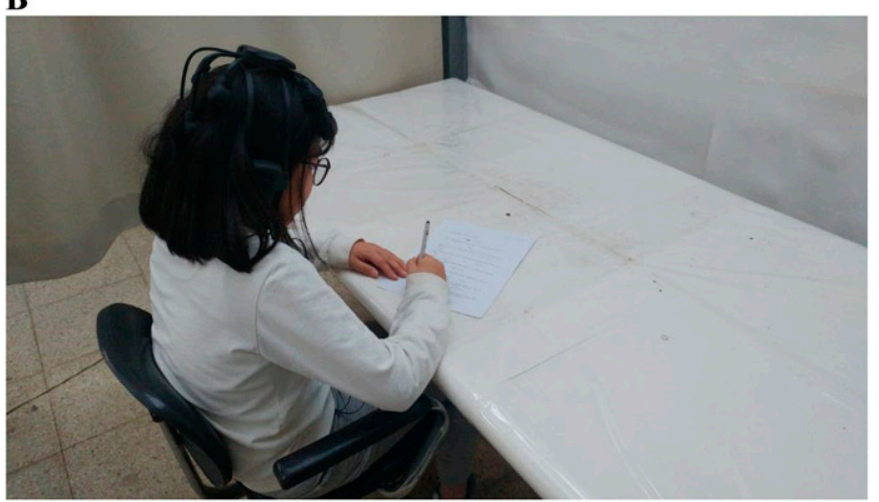

Fig. 2. Intensive assignment conducted (A) with foliage plants or (B) without foliage plants. 
A

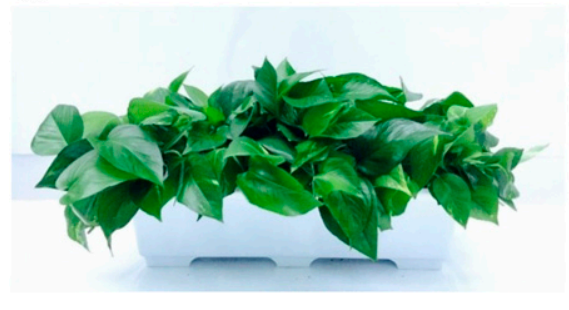

B

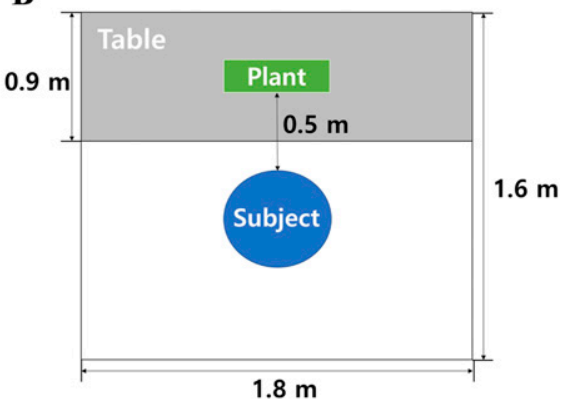

Fig. 3. Experimental setting of the study: (A) plant material and (B) room arrangement for the experiment.

$\mathbf{A}$

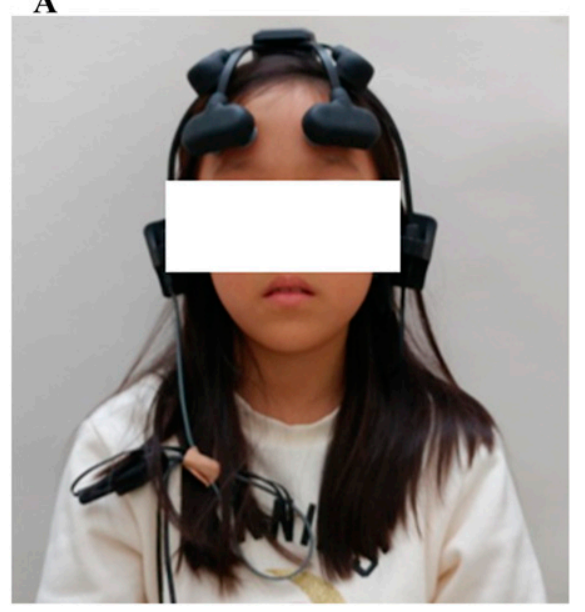

B

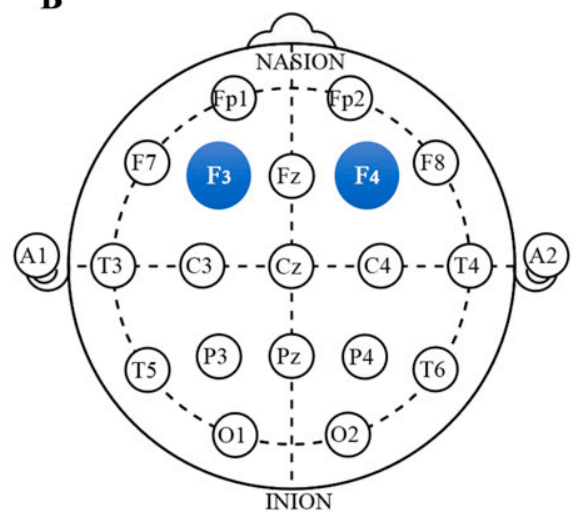

Fig. 4. (A) Wireless dry electroencephalography device (Quick-20; Cognionics, San Diego, CA). (B) International electrode arrangement (Jasper, 1958). The highlighted bolded channels (F3, F4) were measured in this study.

Table 1. Descriptive information of subjects who participated in the study to measure psychophysiological response according to the presence of foliage plants during an intensive assignment $(\mathrm{N}=30)$.

\begin{tabular}{lcccc}
\hline & Male $(\mathrm{n}=10)$ & Female $(\mathrm{n}=20)$ & Total $(\mathrm{N}=30)$ & \\
\cline { 2 - 3 } Variable & \multicolumn{3}{c}{ Mean $\pm \mathrm{sD}$} & Significance $^{\mathrm{w}}$ \\
\hline Age $(\mathrm{yr})$ & $11.9 \pm 1.1$ & $11.5 \pm 1.3$ & $11.6 \pm 1.2$ & $0.964^{\mathrm{NS}}$ \\
Height $^{\mathrm{z}}(\mathrm{cm})$ & $151.7 \pm 10.1$ & $142.9 \pm 10.6$ & $145.8 \pm 11.1$ & $0.149^{\mathrm{NS}}$ \\
Body weight $^{\mathrm{y}}(\mathrm{kg})$ & $49.2 \pm 11.8$ & $37.4 \pm 9.9$ & $41.3 \pm 11.8$ & $0.053^{\mathrm{NS}}$ \\
Body mass index $^{\mathrm{x}}\left(\mathrm{kg} \cdot \mathrm{m}^{-2}\right)$ & $21.2 \pm 3.6$ & $18.0 \pm 2.6$ & $19.0 \pm 3.3$ & $0.053^{\mathrm{NS}}$ \\
\hline
\end{tabular}

${ }^{\mathrm{z}}$ Height was measured using an anthropometer (Ok7979; Samhwa, Seoul, South Korea) without shoes.

${ }^{\mathrm{y}}$ Body weight was measured using a body fat analyzer (ioi 353; Jawon Medical, South Korea).

${ }^{\mathrm{x}}$ Body mass index was calculated using the formula [weight $\left.(\mathrm{kg})\right] /\left[\right.$ height $\left.(\mathrm{m})^{2}\right]$.

${ }^{\mathrm{w}}$ Statistical significance as determined using the independent two-sample $t$ test.

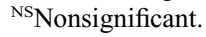

Table 2. Results of relative theta power spectrum (RT), relative beta power spectrum (RB), and ratio of beta wave and theta wave (RBT) by electroencephalography, according to the presence and absence of foliage plants during an intensive assignment.

\begin{tabular}{|c|c|c|c|c|c|c|c|}
\hline & \multirow{4}{*}{$\frac{\text { Plant arrangement }}{\text { Presence }}$} & \multicolumn{2}{|c|}{$\mathrm{RT}^{\mathrm{y}}$} & \multicolumn{2}{|c|}{$R^{x}$} & \multicolumn{2}{|c|}{$\mathrm{RBT}^{\mathrm{w}}$} \\
\hline & & F3 & F4 & F3 & F4 & F3 & F4 \\
\hline \multirow{2}{*}{$\begin{array}{l}\text { EEG } \\
\text { Male }(\mathrm{n}=10)\end{array}$} & & \multicolumn{6}{|c|}{ Mean $\pm \mathrm{SD}^{z}$} \\
\hline & & $0.39 \pm 0.07$ & $0.38 \pm 0.05$ & $0.18 \pm 0.05$ & $0.19 \pm 0.05$ & $0.40 \pm 0.15$ & $0.41 \pm 0.14$ \\
\hline \multirow[t]{3}{*}{ Female $(n=20)$} & Presence & $0.46 \pm 0.10$ & $0.48 \pm 0.13$ & $0.18 \pm 0.05$ & $0.18 \pm 0.06$ & $0.36 \pm 0.16$ & $0.34 \pm 0.18$ \\
\hline & Absence & $0.46 \pm 0.11$ & $0.47 \pm 0.14$ & $0.18 \pm 0.06$ & $0.18 \pm 0.07$ & $0.38 \pm 0.25$ & $0.42 \pm 0.40$ \\
\hline & Significance $^{\mathrm{v}}$ & $1.000^{\mathrm{NS}}$ & $0.766^{\mathrm{NS}}$ & $0.892^{\mathrm{NS}}$ & $0.725^{\mathrm{NS}}$ & $0.957^{\mathrm{NS}}$ & $0.705^{\mathrm{NS}}$ \\
\hline Total $(\mathrm{N}=30)$ & Significance $^{\mathrm{u}}$ & $0.701^{\mathrm{NS}}$ & $0.519^{\mathrm{NS}}$ & $0.831^{\mathrm{NS}}$ & $0.852^{\mathrm{NS}}$ & $0.574^{\mathrm{NS}}$ & $0.693^{\mathrm{NS}}$ \\
\hline
\end{tabular}

${ }^{\mathrm{z}}$ Standard devation.

${ }^{\mathrm{y}} \mathrm{RT}$ was calculated by [theta $(4-7 \mathrm{~Hz})$ power] / [total frequency $(4-50 \mathrm{~Hz})$ power].

${ }^{\mathrm{x}} \mathrm{RB}$ was calculated by [beta $(14-30 \mathrm{~Hz})$ power] / [total frequency $(4-50 \mathrm{~Hz})$ power].

${ }^{\mathrm{w}} \mathrm{RBT}$ was calculated by [beta $(14-30 \mathrm{~Hz})$ power] / [theta $(4-7 \mathrm{~Hz})$ power].

${ }^{\mathrm{v}}$ Statistical significance as determined using Mann-Whitney test.

${ }^{\mathrm{u}} \mathrm{S}$ tatistical significance as determined using the independent two-sample $t$ test.

NS, *Nonsignificant or significant at $P \leq 0.05$. the number of questions solved and the number of correct answers per total number of questions were calculated as a percentage using Microsoft Excel (Office 2007; Microsoft Corp., Redmond, WA).

The independent two-sample $t$ test and Mann-Whitney test in SPSS (version 22 for Windows; IBM, Armonk, NY) were performed; $P<0.05$ was considered statistically significant. For demographic information, Microsoft Excel (Office 2007) was used to generate descriptive statistics of the mean, SD, and percentage.

\section{Results}

Demographic characteristics. Thirty subjects aged $11.6 \pm 1.1$ years participated in the study: 10 boys and 20 girls (boys $11.9 \pm 1.1$ years, girls $11.5 \pm 1.3$ years) (Table 1 ). Boys were found to be in the BMI 75th percentile for 11-year-old boys in South Korea and girls in the BMI 50th percentile of the 11-year-old girls in South Korea (Korea Centers for Disease Control and Prevention, 2017). Both were in the normal range.

Comparisons of concentration in the presence or absence of foliage plants during intensive assignment. In the presence of foliage plants, the RT index was significantly decreased to 0.38 in the right frontal lobe of male subjects compared with that in the absence of foliage plants $(P<0.05)$ (Table 2, Fig. 5). This result indicates an increase in attention and concentration due to the reduction in theta power, which is the reverse index of attention and concentration (Han and Hong, 2017). However, for combined male and female students and female students, there were no differences in the RT index according to the presence and absence of foliage plants during an intensive assignment. Furthermore, there were no differences according to the presence of plants in the RB index and RBT index of combined male and female students (Table 2; brain-mapping data 


\section{Male $(n=10)$}
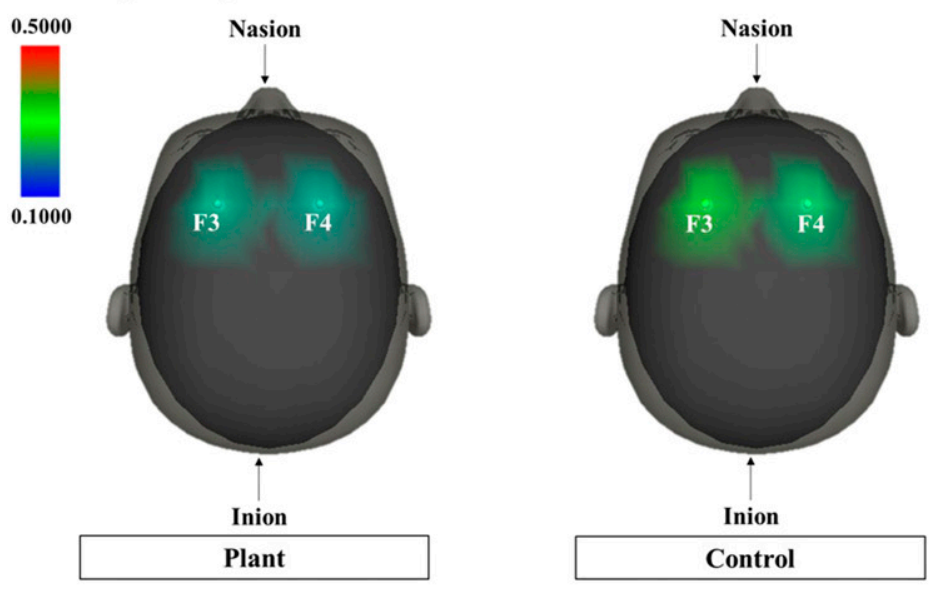

\section{Female $(\mathbf{n}=\mathbf{2 0})$}
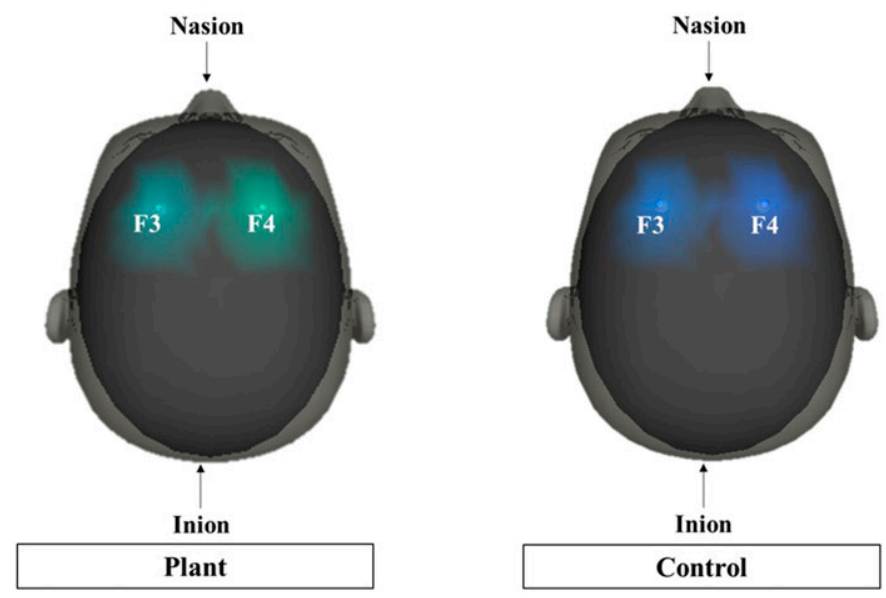

\section{Total $(\mathbf{N}=\mathbf{3 0})$}
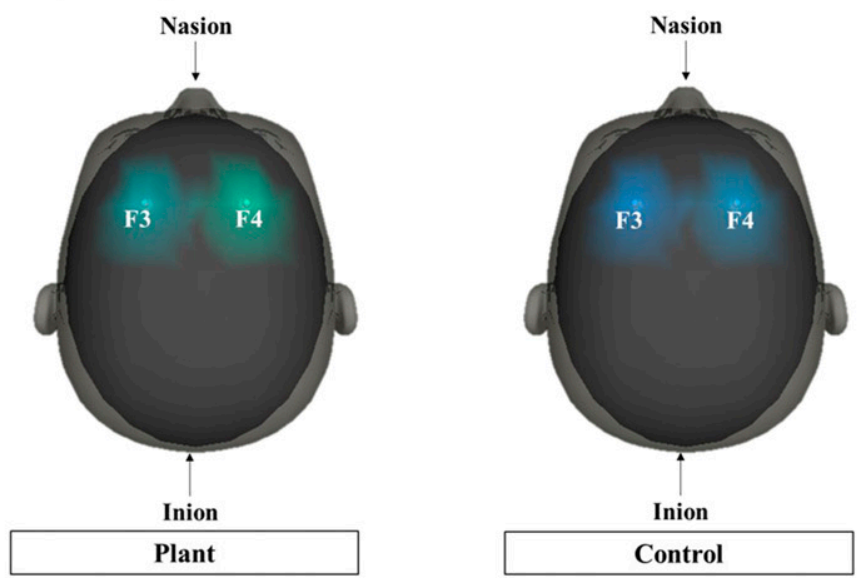

Fig. 5. Relative theta wave intensity using a brain-mapping program according to the presence and absence of foliage plants during an intensive assignment.

not shown). When performing the assignment in the presence of plants, the RLB index in both frontal lobes of male subjects tended to be higher than that when foliage plants were absent; however, the differences were not statistically significant (Table 3 ; brainmapping data not shown). When performing the assignment in the presence of foliage plants, the SEF50 in the right frontal lobe of male subjects was 9.03 , which was significantly higher than that when foliage plants were absent $(P<0.05)$ (Table 4, Fig. 6). Because the SEF50 tends to increase with increasing attention and assignment difficulty (Park and Goo, 2007), this result means the brain activity of male subjects when perform- ing the assignment in the presence of foliage plants was activated (Schwarz et al., 2004). Furthermore, the data for combined male and female students and female students showed that there were no differences in the SEF50 according to the presence and absence of foliage plants during an intensive assignment.

Comparison of emotional condition in the presence or absence of foliage plants under an intensive assignment. Subjective evaluation of emotional condition according to the presence and absence of foliage plants when performing the assignment was performed using the SDM questionnaire. According to the SDM, the feeling of "being relaxed" was significantly higher with foliage plants (the value was $\approx 1.3$ ) than without foliage plants (the value was $\approx 0.3)(P<0.05)$ (Fig. 7). Furthermore, there were no statistically significant differences in the feeling of "being comfortable" and "being natural" (Fig. 7). The results of classification by gender revealed that there were no statistically significant differences in the SDM according to the presence and absence of foliage plants (data not shown).

Result of intensive assignment performance. The results of the intensive assignment performance according to the presence or absence of foliage plants revealed that the performance of male students in the presence of plants was significantly higher than that in the absence of plants, from 5.70 to 8.20 within the same time $(P<0.05)$ (Fig. 8). Furthermore, the percentage of correct answers in the assignment in the presence of plants was higher than that in the absence of plants, from $36.00 \%$ to $52.67 \%$ in male students $(P<0.05)$ (Table 5). The results of the intensive assignment performance and percentage of correct answers in the assignment of female students and total students revealed that there were no statistically significant differences according to the presence and absence of foliage plants (Table 5, Fig. 8).

\section{Discussion}

To compare concentration and emotional condition of elementary school students who performed an intensive assignment in the presence or absence of foliage plants, the EEG monitoring and a modified SDM were performed. The results revealed that the concentration of male elementary students was significantly higher when the assignment was performed in the presence vs. absence of plants as evidenced by the increase in the ratio of SEF50 and the decrease in the relative theta power spectrum in the right frontal lobe. Per the SDM, significant psychological relaxation was demonstrated when the assignment was performed in the presence of plants.

In the presence of foliage plants, the RT index was significantly decreased in the right frontal lobe of male subjects compared with that in the absence of foliage plants; there were no significant differences in the RB, RBT, and RLB indexes according to the 
Table 3. Results of relative low-beta wave (RLB) by electroencephalography, according to the presence or absence of foliage plants during an intensive assignment.

\begin{tabular}{llcc}
\hline & & $\mathrm{F} 3$ & $\mathrm{~F} 4$ \\
\cline { 3 - 4 } RLB $^{\mathrm{y}}$ & Plant arrangement & \multicolumn{2}{c}{ Mean $\pm \mathrm{SD}^{\mathrm{z}}$} \\
\hline Male $(\mathrm{n}=10)$ & Presence & $0.16 \pm 0.04$ & $0.15 \pm 0.05$ \\
& Absence & $0.15 \pm 0.05$ & $0.14 \pm 0.05$ \\
Female $(\mathrm{n}=20)$ & Significance & $0.775^{\mathrm{NS}}$ & $0.619^{\mathrm{NS}}$ \\
& Presence & $0.13 \pm 0.04$ & $0.13 \pm 0.03$ \\
& Absence & $0.14 \pm 0.04$ & $0.13 \pm 0.05$ \\
Total $(\mathrm{N}=30)$ & Significance & $0.850^{\mathrm{NS}}$ & $0.534^{\mathrm{NS}}$ \\
& Presence & $0.14 \pm 0.04$ & $0.14 \pm 0.04$ \\
& Absence & $0.14 \pm 0.04$ & $0.14 \pm 0.05$ \\
& Significance & & $0.824^{\mathrm{NS}}$ \\
\hline
\end{tabular}

${ }^{\mathrm{z}}$ Standard devation.

${ }^{\mathrm{y}} \mathrm{RLB}$ was calculated by [low-beta $(12-15 \mathrm{~Hz})$ power] / [total frequency $(4-50 \mathrm{~Hz})$ power].

${ }^{\mathrm{x}}$ Statistical significance as determined using Mann-Whitney test.

${ }^{\mathrm{w}}$ Statistical significance as determined using the independent two-sample $t$ test.

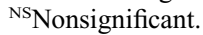

Table 4. Results of spectral edge frequency of 50 (SEF50) using electroencephalography, according to the presence or absence of foliage plants during an intensive assignment.

\begin{tabular}{llcc}
\hline & & $\mathrm{F} 3(\mathrm{~Hz})$ & $\mathrm{F} 4(\mathrm{~Hz})$ \\
\cline { 3 - 4 } SEF50 & Plant arrangement & $8.98 \pm 2.44$ & $\mathrm{Mean}^{\mathrm{y}} \pm \mathrm{SD}^{\mathrm{z}}$ \\
\hline Male $(\mathrm{n}=10)$ & Presence & $7.98 \pm 1.13$ & $9.03 \pm 2.25$ \\
& Absence & $0.333^{\mathrm{NS}}$ & $7.45 \pm 1.36$ \\
& Significance & $7.68 \pm 1.05$ & $0.028^{*}$ \\
Female $(\mathrm{n}=20)$ & Presence & $7.95 \pm 1.66$ & $7.64 \pm 1.37$ \\
& Absence & $0.776^{\mathrm{NS}}$ & $8.08 \pm 2.60$ \\
& Significance & $8.11 \pm 1.72$ & $0.839^{\mathrm{NS}}$ \\
Total $(\mathrm{N}=30)$ & Presence & $7.96 \pm 1.48$ & $8.10 \pm 1.80$ \\
& Absence & $0.720^{\mathrm{NS}}$ & $7.87 \pm 2.26$ \\
& Significance & & $0.661^{\mathrm{NS}}$ \\
\hline
\end{tabular}

${ }^{\mathrm{z}}$ Standard devation.

${ }^{y} \mathrm{SEF} 50$ is the area from 4 to $50 \mathrm{~Hz}$, which occupies $50 \%$ of the area in the entire frequency range.

${ }^{\mathrm{x}}$ Statistical significance as determined using Mann-Whitney test.

${ }^{\mathrm{w}}$ Statistical significance as determined using the independent two-sample $t$ test.

Ns, *Nonsignificant or significant at $P \leq 0.05$.

Table 5. Percentage of correct answers in intensive assignment according to the presence and absence of foliage plants.

\begin{tabular}{lccc}
\hline & With foliage plants & Without foliage plants & Significance \\
\cline { 2 - 4 } Percentage of correct answers $(\%)$ & \multicolumn{3}{c}{ Mean $\pm \mathrm{sD}^{\mathrm{z}}$} \\
\hline Total $(\mathrm{N}=30)$ & $38.89 \pm 26.38$ & $34.89 \pm 21.28$ & $0.261^{\text {NS, y }}$ \\
Male $(\mathrm{n}=10)$ & $52.67 \pm 24.64$ & $36.00 \pm 16.69$ & $0.031^{*, \mathrm{x}}$ \\
Female $(\mathrm{n}=20)$ & $32.00 \pm 25.00$ & $34.33 \pm 23.62$ & $0.377^{\text {NS, }}$ \\
\hline
\end{tabular}

${ }^{\mathrm{z}}$ Standard devation.

${ }^{\mathrm{y}}$ Statistical significance as determined using Mann-Whitney test.

${ }^{\mathrm{x}}$ Statistical significance as determined using the independent two-sample $t$ test.

NS, *Nonsignificant or significant at $P \leq 0.05$.

presence and absence of foliage plants during an intensive assignment (Tables 2 and 3 ). Previous findings suggest that theta wave, beta wave, and ratio of beta wave and theta wave are indicators of frontal lobe functional status in relation to attention and concentration (Choi, 2011). Among these, the theta waves in the 4- to $7-\mathrm{Hz}$ range occurs in a shallow sleep state or during rapid eye movement sleep (Han and Hong, 2017). When theta waves are overloaded while studying in adolescence, the brain is in a shallow sleep rather than attention (Byun, 2011). If this condition persists, learning efficiency is reduced, and other problems, such as lack of motivation, occur (Byun, 2011). If the intensity of theta waves is higher than that required by age, it means that the degree of attention and brain activity is low (Clarke et al., 2002). In particular, ADHD can be regarded as a representative disorder of
In the presence of foliage plants, the SEF50 was significantly increased in the right frontal lobe of male subjects compared with that in the absence of foliage plants (Table 4, Fig. 6). Because SEF50 is the frequency below $50 \%$ of the total EEG power (Schwender et al., 1996), it is a measure used to investigate the activity of the cerebral cortex and indicates the degree of workload (Yu et al., 2012). The SEF50 is an index for the awake state that shows how much of the brain is active during a task (Schwarz et al., 2004). It is also an indicator of the degree of cognitive load in the brain - the higher the value, the higher the cognitive ability (Tak, 2010). Therefore, male students who performed the assignment in the space where plants were present could improve their attention because the brain was more awake and cognitive activation occurred. Similar results have been reported in previous studies on the benefits of plant arrangement in the work environment. Jang (2013) and Lee and Son (1999) reported that cerebral activity increased when looking at plants. Igarashi et al. (2015) reported that the frontal lobe was activated when looking at living plants rather plant images. There is evidence that, as a whole, the prefrontal cortex that is the front part of frontal lobe in the cerebral cortex performs a critical role in the organization of behavioral, linguistic, and cognitive actions; therefore, the activation of frontal lobe indicates an improvement in intellectual performance ability and attention ability (Carter, 2009; Fuster, 2002; Marie and Rebecca, 2011).

The results of the intensive assignment performance and the percentage of correct answers in the assignment according to the presence and absence of foliage plants revealed that the assignment achievement and the percentage of correct answers of male students in the presence of plants was significantly higher than that in the absence of plants (Table 5). A similar study revealed that contact with plants has positive effects on intellectual performance ability and that the higher the ratio of natural scenery outside the window, the higher the symbol digit modalities test achievement of girls aged 7 to 12 years (Taylor et al., 2002). According to a study by Tennessen and Cimprich (1995), 72 college students performed attention tasks such as Digit Span Forwards, Digit Span Backward, and Symbol Digit Modalities Test in their dormitories, and the task achievement increased as the ratio of natural scenery outside the window increased. In another study, after 25 children who were diagnosed with ADHD walked 20 min in the city or park, children who walked in the park performed better on an attention task (Digit Span Backward) than those who walked in the city (Taylor and Kuo, 2009).

Based on the SDM, according to the presence and absence of foliage plants when performing the assignment, the feeling of "being relaxed" was significantly higher with plants than without plants (Fig. 7). 


\section{Male ( $n=10)$}
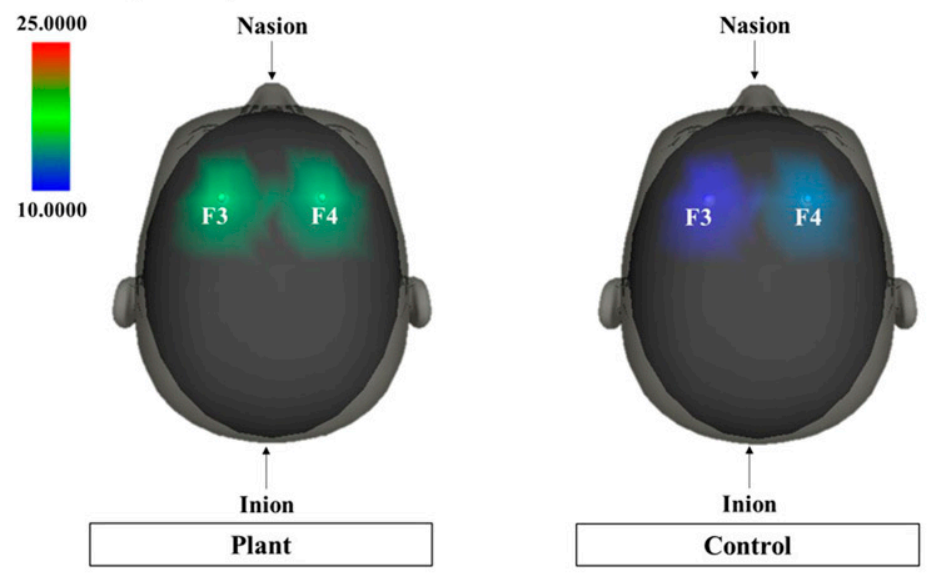

\section{Female $(n=20)$}
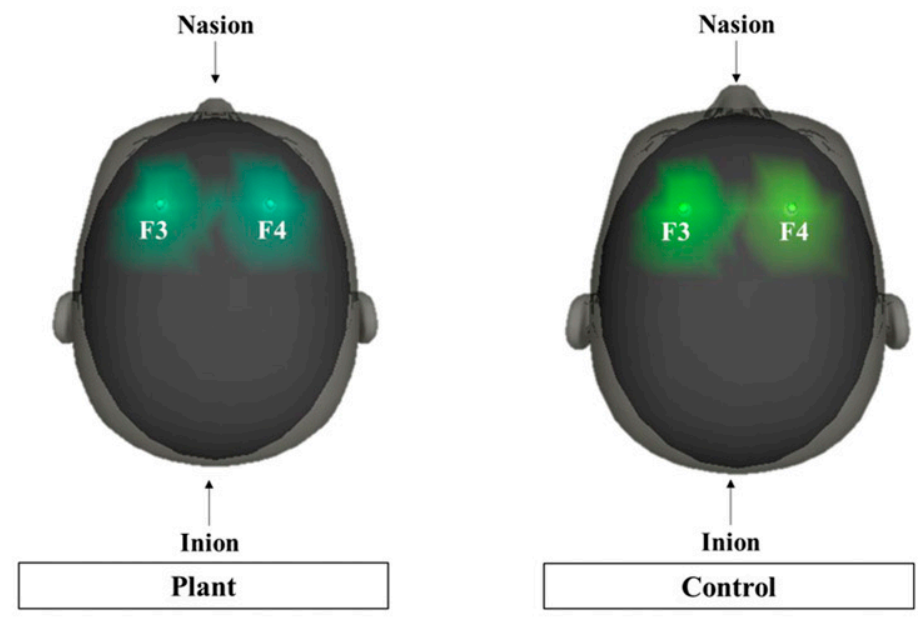

\section{Total $(\mathbf{N}=\mathbf{3 0})$}
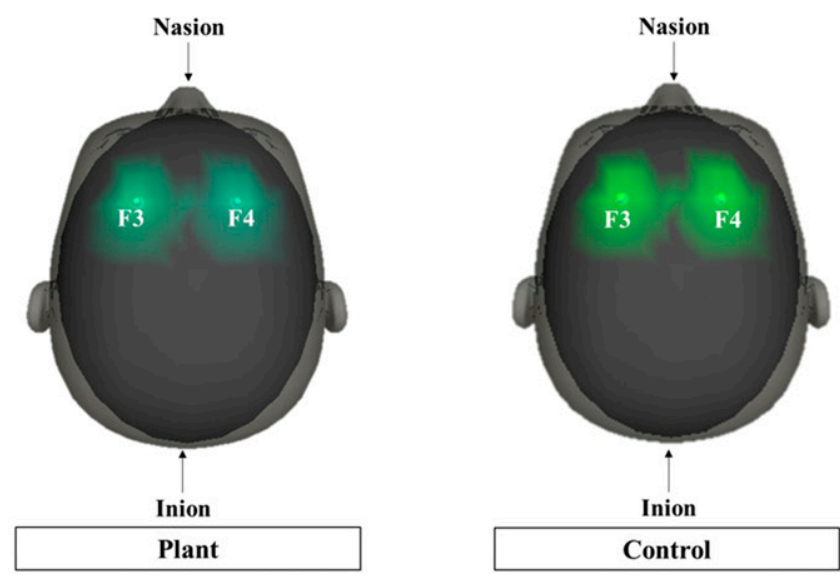

Fig. 6. Relative spectral edge frequency of 50 using a brain-mapping program according to the presence or absence of foliage plants during an intensive assignment $(\mathrm{Hz})$.

Similar findings have been reported in previous studies. When 24 men in their 20 s performed the same tasks with and without foliage plants, the oxyhemoglobin concentration in the left prefrontal cortex of the subjects was lowered when performing the task with plants; this result suggests that tasks involving living foliage plants induce more physiological relaxation than working without foliage plants (Park et al., 2017). Furthermore, they also felt significant positive emotions, such as being more comfortable, natural, and relaxed compared with performing the task without plants (Park et al., 2017). According to Choi et al. (2016), only a 5\% index of indoor greenness could provide benefits in psychophysiological stability by stimulating the autonomic nervous system, such as EEG and heart rate variability, and is associated with positive feelings such as "clean," "soft," "bright," "warm," "vibrant," "comfortable," and "fresh."

The results of this study reveal that there were differences in children's EEG response and assignment performance according to the presence or absence of foliage plants during the intensive assignment between genders. According to previous studies, there are large numbers of androgen receptors in the visual cortex of the brain, and males have higher levels of androgens compared with females (Moir, 1992; Nunez et al., 2000). Because of this, neurons in the visual cortex of the brain develop differently, and males show differences in visual function, such as finding changes in minute parts of visual stimuli, compared with females (Abramov et al., 2012). Therefore, in this study, we suggest that male students accepted and responded to the visual stimulation of foliage plants more sensitively according to differences in visual function between genders, which also affected psychophysiological responses and performance on the assignment.

In conclusion, the purpose of the present study was to investigate the effects of exposure to living foliage plants by measuring psychophysiological and psychological indicators when children performed an intensive assignment. The results revealed that the presence of plants in the assignment performance space increased the EEG activity in the frontal lobe and improved concentration for male students. Furthermore, it also made them psychologically stable and promoted positive mood. Further studies should recruit more subjects to analyze more specific psychophysiological and psychological effects of living plants in assignment performance spaces. A follow-up study would be interesting to determine the effect according to the number and types of plants. Moreover, it would be valuable to compare differences among ages and between genders.

\section{Literature Cited}

Abramov, I., J. Gordon, O. Feldman, and A. Chavarga. 2012. Sex \& vision I: Spatiotemporal resolution. Biol. Sex Differ. 3:20.

Asaumi, H. 1995a. Effect of ornamental foliage plants on visual fatigue caused by visual display terminal operation. J. Soc. High Tech. Agr. 7:138-143.

Asaumi, H. 1995b. Evaluation of impression of ornamental foliage plants and psychological rating of rooms with ornamental foliage plants by means of semantic differential method. J. SHITA 7:34-45.

Asaumi, H., H. Nishina, K. Tsukanishi, Y. Masui, and Y. Hashimoto. 1994. Effects of foliage plants on thermal environment and comfort inside room-experimental analysis in winter. J. Archit. Plann. Environ. Eng. AIJ 464:39-46.

Bakhtadze, S., M. Beridze, N. Geladze, N. Khachapuridze, and N. Bornstein. 2016. Effect of EEG biofeedback on cognitive flexibility in children with attention deficit hyperactivity disorder with and without epilepsy. Appl. Psychophysiol. Biofeedback 41:71-79. 

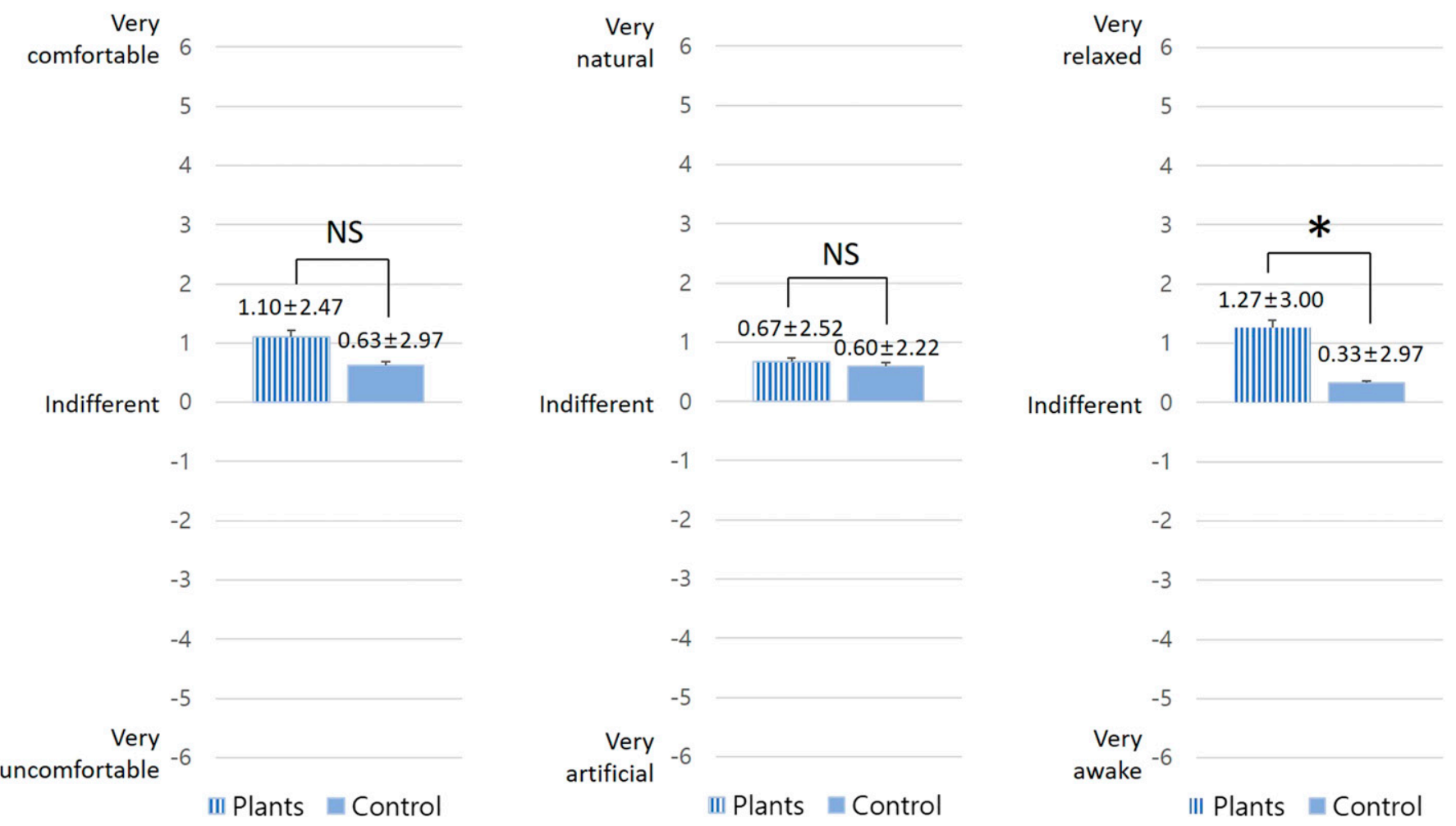

Fig. 7. Results of modified semantic differential method (SDM), according to the presence and absence of foliage plants during an intensive assignment $(\mathrm{N}=30)$. $\mathrm{NS}=$ not significant, $* P<0.05,{ }^{*} P<0.01,{ }^{* * *} P<0.001$ by independent two-sample $t$ test.

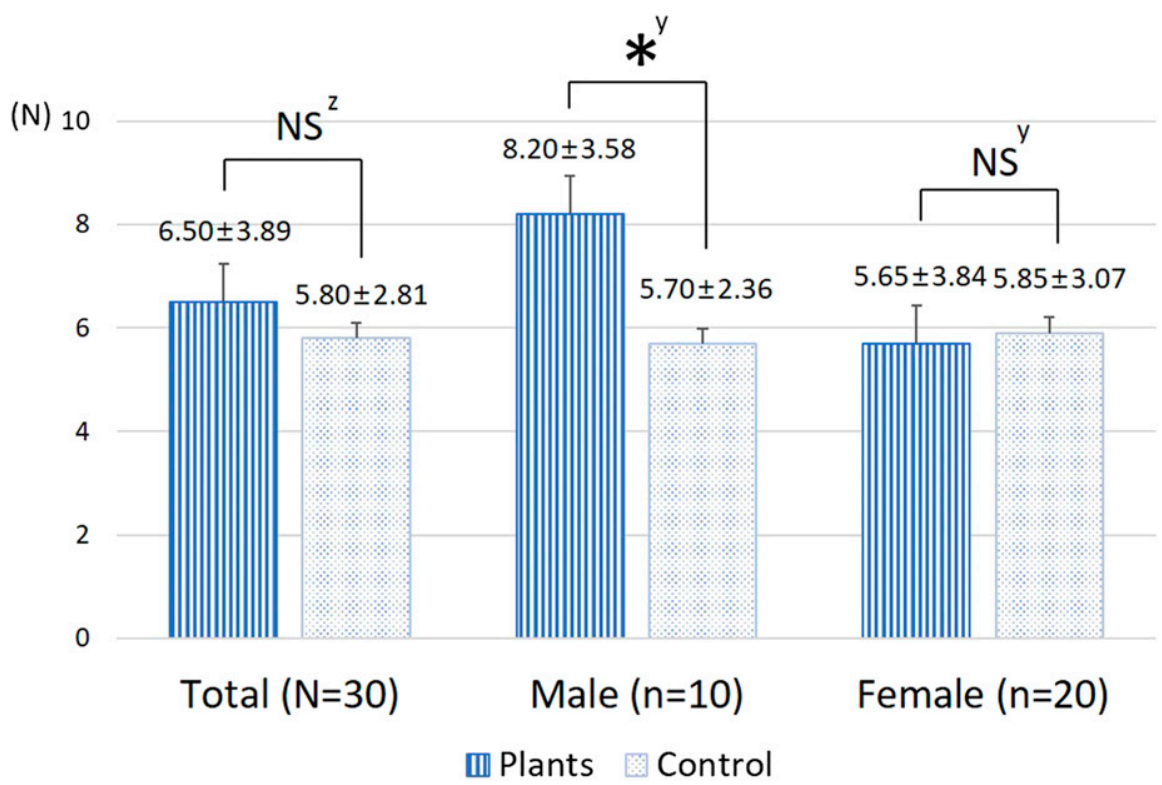

Fig. 8. Results of number of assignments performed according to the presence and absence of foliage plants during an intensive assignment. NS $=$ nonsignificant, ${ }^{*} P<0.05 .{ }^{z}$ Independent two-sample $t$ test. ${ }^{\mathrm{y}}$ Mann-Whitney test.

Bradshaw, J., B. Martorano, L. Natali, and C. de Neubourg. 2013. Children's subjective wellbeing in rich countries. Child Inst. Res. 6:619635.

Byun, Y.E. 2011. The effect of neurofeedback training on age differences groups in adolescence. J. Kor. Acad. Ind. Coop. Soc. 12:25612566.

Carter, R. 2009. The human brain book: An illustrated guide to its structure, function, and disorders. Penguin, London.
Choi, S.M. 2017. Fast computation for busy 3th and 4th graders-division. Essysedu, Seoul.

Choi, Y.H. 2011. Analysis of electroencephalogram (EEG) activities of middle school students in technological problem solving thinking process as levels of structured problem. J. Kor. P. Arts Educ. 17:129-152.

Clarke, A.R., R.J. Barry, R. McCarthy, and M. Selikowitz. 2002. Children with attention-deficit/ hyperactivity disorder and comorbid oppositional defiant disorder: An EEG analysis. Psychiatry Res. 111:181-190.

Dye, C. 2008. Health and urban living. Science 319:766-769.

Fuster, J.M. 2002. Frontal lobe and cognitive development. J. Neurocytol. 31:373-385.

Han, Y.J. and C.H. Hong. 2017. The effects of neurofeedback on the attention in college students with ADHD. J. Kor. Acad. Ind. Coop. Soc. 18:245-255.

Heckman, M.A., J. Weil, and E.G. De Mejia. 2010. Caffeine (1, 3, 7-trimethylxanthine) in foods: A comprehensive review on consumption, functionality, safety, and regulatory matters. J. Food Sci. 75:R77-R87.

Igarashi, M., C. Song, H. Ikei, and Y. Miyazaki. 2015. Effect of stimulation by foliage plant display images on prefrontal cortex activity: A comparison with stimulation using actual foliage plants. J. Neuroimaging 25:127-130.

Jang, H.S. 2013. Influences of visual element of ornamental plants to emotion or electroencephalography of human. Korea Univ., Seoul, MS Diss. response to window views and indoor plant in the workplace. HortScience 40:13541359.

Choi, J.Y., S.A. Park, S.J. Jung, J.Y. Lee, K.C. Son, Y.J. An, and S.W. Lee. 2016. Physiological and psychological responses of humans to the index of greenness of an interior space. Complement. Ther. Med. 28:37-43.

Choi, S.M. 2015. Fast computation for busy 3 th and 4th graders- multiplication. Essysedu, Seoul.

Jasper, H.H. 1958. The ten-twenty electrode system of the international federation. Electroencephalogr. Clin. Neurophysiol. 10:370-375.

Jeon, J.H. 2009. A study on the international comparative analysis of children and young adult in life patterns. Ministry for Health, Welfare and Family Affairs, Seoul. 
Kang, N.Y. and S.M. Choi. 2015. Fast computation for busy 5 th and 6 th graders-multiplication. Essysedu, Seoul.

Kang, N.Y. and S.M. Choi. 2017. Fast computation for busy 5 th and 6 th graders-division. Essysedu, Seoul.

Kim, M.S. 2015. The subjective well-being of Korean children and its policy implications. In Health and welfare policy forum. Korea Institute for Health and Social Affairs, Sejong.

Kondo, M. 1989. Experimental research on the effectiveness of using green in reducing of visual fatigue caused by VDT operation. J. Jpn. Inst. Landsc. Archit. 52:139-144.

Korea Centers for Disease Control and Prevention. 2017. 2017 Korean national growth charts for children and adolescents. Korea Centers Dis. Control Prevention, Cheongju.

Lee, E.J. and J.H. Kim. 2017a. A study of consumer's emotional response on musical stimulus through EEG analysis: Based on color perception of consumers. Kor. J. Bus. Admin. 30:2147-2172.

Lee, J.S. and K.C. Son. 1999. Effects of indoor plant and various colors' stimuli on the changes of brain activity and emotional responses. Hort. Environ. Biotechnol. 40:772-776.

Lee, Y.J. and M.H. Kim. 2017b. Multi-sensory stimulation method for concentration improvement of the university's library. Int. Inf. Inst. (Tokyo). Inform 20:6011-6018.

Marie, T.B. and J.C. Rebecca. 2011. Cognitive neuroscience. 3rd ed. Cengage Learning, Boston.

Markevych, I., C.M. Tiesler, E. Fuertes, M. Romanos, P. Dadvand, M.J. Nieuwenhuijsen, E. Berdel, S. Koletzko, and J. Heinrich. 2014. Access to urban green spaces and behavioural problems in children: Results from the GINIplus and LISAplus studies. Environ. Int. 71:29-35.

Mohammadi, M.R., N. Malmir, A. Khaleghi, and M. Aminiorani. 2015. Comparison of sensorimotor rhythm (SMR) and beta training on selective attention and symptoms in children with attention deficit/hyperactivity disorder (ADHD): A trend report. Iran. J. Psychiatry 10:165-174.

Moir, A. 1992. Brain sex: The real difference between men and women. Wise Owl Secrets, London.
Monderer, R., D.M. Harrison, and S.R. Hauta. 2002. Neurofeedback and epilepsy. Epilepsy Behav. 3:214-218.

Montessori, M. 2013. The montessori method. Wilder Publications, New York.

Nunez, J.L., A.J. Heidi, and M.J. Janice. 2000 Androgens reduce cell death in the developing rat visual cortex. Brain Res. Dev. Brain Res. 125:83-88.

OECD. 2017. PISA 2015 results (volume III): Students' well-being. OECD Publishing, Paris

Oh, Y.A., S.O. Kim, and S.A. Park. 2019. Real foliage plants as visual stimuli to improve concentration and attention in elementary students. Int. J. Environ. Res. Public Health 16:796.

Onton, J.A., D.Y. Kang, and T.P. Coleman. 2016. Visualization of whole-night sleep EEG from 2-channel mobile recording device reveals distinct deep sleep stages with differential electrodermal activity. Front. Hum. Neurosci. 10:605.

Osgood, C.E., S.J. Suci, and P.H. Tannnenbaum. 1957. The measurement of meaning. Illinois Univ. Press, Champaign, IL.

Park, B.W. 2005. Introduction to neurofeedback. Korea Mental Health Institute, Seoul.

Park, K.S. and J.Y. Goo. 2007. A study of evaluating VR learning styles on user attention and memory. J. Inf. Process Syst. 14:119-126.

Park, S.A., C.R. Song, Y.A. Oh, Y. Miyazaki, and K.C. Son. 2017. Comparison of physiological and psychological relaxation using measurements of heart rate variability, prefrontal cortex activity, and subjective indexes after completing tasks with and without foliage plants. Int. J. Environ. Res. Public Health 14:1087.

Schwarz, G., H. Voit-Augustin, G. Litscher, and A. Baumgartner. 2004. Specific problems in interpretation of absolute values of spectral edge frequency (SEF) in comparison to bispectral index (BIS) for assessing depth of anesthesia. Internet J. Neuromonitoring. 3, doi: 10.5580/ $12 \mathrm{ca}$.

Schwender, D., M. Daunderer, S. Mulzer, S. Klasing, U. Finsterer, and K. Peter. 1996. Spectral edge frequency of the electroencephalogram to mon- itor "depth" of anaesthesia with isoflurane or propofol. Br. J. Anaesth. 77:179-184.

Sin, Y.S. and Y.S. Kang. 2001. Educational administration management. Education Editorial, Seoul.

Sterman, M.B. and T. Egner. 2006. Foundation and practice of neurofeedback for the treatment of epilepsy. Appl. Psychophysiol. Biofeedback 21, doi: 10.1007/s10484-006-9002-x.

Stevens, R., T. Galloway, D. Halpin, and A. Willemsen-Dunlap. 2016. Healthcare teams neurodynamically reorganize when resolving uncertainty. Entropy 18:427.

Suh, J.K., H.J. Yoon, T.S. Kim, J.H. Kim, A.R. Cho, B.W. Lee, and H.W. Lim. 2016. Korean exposure factors handbook for children. National Institute of Environmental Research, Incheon.

Tak, J.S. 2010. EEG differences between gifted students and average onces in information science. Korea Natl. Univ. Educ, Cheongju, MS Thesis.

Tarkka, I.M. and M. Hallett. 1990. Cortical topography of premotor and motor potentials preceding self-paced, voluntary movement of dominant and non-dominant hands. Electroencephalogr. Clin. Neurophysiol. 75:36-43.

Taylor, A.F. and F.E. Kuo. 2009. Children with attention deficits concentrate better after walk in the park. J. Atten. Disord. 12:402-409.

Taylor, A.F., F.E. Kuo, and W.C. Sullivan. 2002. Views of nature and self-discipline: Evidence from inner city children. J. Environ. Psychol. 22:49-63.

Tennessen, C.M. and B. Cimprich. 1995. Views to nature: Effects on attention. J. Environ. Psychol. 15:77-85

Ulrich, R.S. 1984. View through a window may influence recovery from surgery. Science 224:420-421.

Yu, J., H. Kang, and J. Jung. 2012. Effects of neurofeedback on brain waves and cognitive functions of children with cerebral palsy: A randomized control trial. J. Phys. Ther. Sci. 24:809-812. 